\title{
Low dose oestrogen combined oral contraception and risk of pulmonary embolism, stroke, and myocardial infarction in five million French women: cohort study
}

\author{
Alain Weill,1 Marie Dalichampt,, Fanny Raguideau,2 Philippe Ricordeau, ${ }^{1}$ Pierre-Olivier Blotière, ${ }^{1}$ \\ Jérémie Rudant, ${ }^{1}$ François Alla, ${ }^{1}$ Mahmoud Zureik ${ }^{2}$
}

1Department of Studies in

Public Health, French National

Health Insurance, 75986 Paris

Cedex 20, France

2French National Agency for Medicines and Health Products Safety, Saint-Denis, France

Correspondence to: A Weill alain.weill@cnamts.fr

Additional material is published online only. To view please visit

the journal online.

Cite this as: $B M / 2016 ; 353: 12002$ http://dx.doi.org/10.1136/bmj.i2002

Accepted: 22 March 2016

\section{ABSTRACT}

\section{OBJECTIVE}

To assess the risk of pulmonary embolism, ischaemic stroke, and myocardial infarction associated with combined oral contraceptives according to dose of oestrogen (ethinylestradiol) and progestogen.

DESIGN

Observational cohort study.

SETTING

Data from the French national health insurance database linked with data from the French national hospital discharge database.

\section{PARTICIPANTS}

4945088 women aged $15-49$ years, living in France, with at least one reimbursement for oral contraceptives and no previous hospital admission for cancer, pulmonary embolism, ischaemic stroke, or myocardial infarction, between July 2010 and September 2012.

\section{MAIN OUTCOME MEASURES}

Relative and absolute risks of first pulmonary embolism, ischaemic stroke, and myocardial infarction.

RESULTS

The cohort generated 5443916 women years of oral contraceptive use, and 3253 events were observed: 1800 pulmonary embolisms (33 per 100000 women years), 1046 ischaemic strokes (19 per 100000 women years), and 407 myocardial infarctions (7 per 100000 women years). After adjustment for progestogen and risk factors, the relative risks for women using low dose oestrogen $(20 \mu \mathrm{g} v 30-40 \mu \mathrm{g})$ were 0.75 ( $95 \%$ confidence interval 0.67 to 0.85 ) for pulmonary embolism, 0.82 (0.70 to 0.96 ) for

\section{WHAT IS ALREADY KNOWN ON THIS TOPIC}

Use of combined oral contraceptives increases the risk of pulmonary embolism A dose related effect of oestrogen (ethinylestradiol) has been observed for the progestogens gestodene, desogestrel, and levonorgestrel, with higher doses associated with a higher risk of venous thromboembolism

The use of oral contraceptives is also associated with an increased risk of ischaemic stroke and myocardial infarction

\section{WHAT THIS STUDY ADDS}

For the same progestogen, using an oestrogen dose of $20 \mu \mathrm{g}$ compared with 30-40 $\mu \mathrm{g}$ was associated with lower risks of pulmonary embolism, ischaemic stroke, and myocardial infarction

Oral contraceptives containing levonorgestrel with $20 \mu \mathrm{g}$ of oestrogen was the combination associated with the overall lowest risk of pulmonary embolism and arterial thromboembolism ischaemic stroke, and 0.56 (0.39 to 0.79$)$ for myocardial infarction. After adjustment for oestrogen dose and risk factors, desogestrel and gestodene were associated with statistically significantly higher relative risks for pulmonary embolism $(2.16,1.93$ to 2.41 and $1.63,1.34$ to 1.97 , respectively) compared with levonorgestrel. Levonorgestrel combined with $20 \mu \mathrm{g}$ oestrogen was associated with a statistically significantly lower risk than levonorgestrel with 30-40 $\mu$ g oestrogen for each of the three serious adverse events.

\section{CONCLUSIONS}

For the same dose of oestrogen, desogestrel and gestodene were associated with statistically significantly higher risks of pulmonary embolism but not arterial thromboembolism compared with levonorgestrel. For the same type of progestogen, an oestrogen dose of $20 \mu \mathrm{g}$ versus 30-40 $\mu \mathrm{g}$ was associated with lower risks of pulmonary embolism, ischaemic stroke, and myocardial infarction.

\section{Introduction}

About 104 million women worldwide use oral contraceptives. ${ }^{1}$ In most countries various types of pills are available, and studies have shown an increased risk of venous thromboembolism with the use of combined oral contraceptives. ${ }^{2-18}$ This risk differs according to type of progestogen and decreases with both duration of use and decreasing oestrogen dose.

The optimal choice of oral contraceptives must also take into account the risks of stroke and myocardial infarction. Few studies have examined this relation, and those that are available have reported conflicting results. ${ }^{19-31}$ The impact and magnitude of the arterial risk according to dose of oestrogen (ethinylestradiol, 20 $\mu \mathrm{g} v$ 30-40 $\mu \mathrm{g}$ ) have not been established for all progestogens. In France, eight combinations were available and reimbursed by national health insurance during the study period (table 1). They differed according to type of progestogen (norethisterone, levonorgestrel, desogestrel, gestodene, norgestrel) and dose of oestrogen $(20 \mu \mathrm{g}$ to $50 \mu \mathrm{g})$.

We assessed, under real life conditions in France, the absolute and relative risk of pulmonary embolism, ischaemic stroke, and myocardial infarction associated with the eight reimbursed oral contraceptives (including levonorgestrel with $20 \mu \mathrm{g}$ oestrogen) according to type of progestogen and dose of oestrogen. The objective was to identify the combination associated with the lowest risk of venous and arterial thromboembolism. 


\begin{tabular}{|c|c|c|c|c|}
\hline \multicolumn{2}{|c|}{ Combined oral contraceptive } & \multirow[b]{2}{*}{$\begin{array}{l}\text { Generation of } \\
\text { progestogen }\end{array}$} & \multirow[b]{2}{*}{$\begin{array}{l}\text { Introduction } \\
\text { to market }\end{array}$} & \multirow{2}{*}{$\begin{array}{l}\text { Start of } \\
\text { reimbursement } \\
\text { by health } \\
\text { insurance }\end{array}$} \\
\hline Progestogen type & $\begin{array}{l}\text { Oestrogen* } \\
\text { dose }\end{array}$ & & & \\
\hline Norethisterone & $35 \mu \mathrm{g}$ & First & 1982 & June 1984 \\
\hline Norgestrel & $50 \mu \mathrm{g}$ & Second & 1973 & February 1975 \\
\hline Levonorgestrel & $30-40 \mu \mathrm{g}$ & Second & 1974 & May 1976 \\
\hline Levonorgestrel & $20 \mu \mathrm{g}$ & Second & Apr-10 & April 2010 \\
\hline Desogestrel & $30 \mu \mathrm{g}$ & Third & 1984 & September 2009 \\
\hline Desogestrel & $20 \mu \mathrm{g}$ & Third & 1988 & January 2010 \\
\hline Gestodene & $30 \mu \mathrm{g}$ & Third & 1988 & November 2010 \\
\hline Gestodene & $20 \mu \mathrm{g}$ & Third & 1995 & November 2010 \\
\hline
\end{tabular}

*Ethinylestradiol. sion. As this study was designed to assess the risk of first pulmonary embolism, stroke, or myocardial infarction, we excluded women with a history of pulmonary embolism (hospital discharge since 2006, ICD-10 codes: I26), ischaemic stroke (hospital discharge since 2006 or long term disease diagnosis, ICD-10: I63-64), myocardial infarction (hospital discharge since 2006, ICD-10: I21, I22), and cancer and neoplastic disease (hospital discharge since 2006 or long term disease diagnosis, ICD-10 codes: C00-C97 and D00-D48) before the date of study entry. Follow-up started from the first reimbursement for oral contraceptives by French national health insurance between July 2010 and September 2012, and ended at the time of the first of the following events: discontinuation of oral contraceptives, hospital discharge for pulmonary embolism or ischaemic stroke or myocardial infarction, onset of pregnancy, age 50, hospital discharge for cancer, hospital discharge after orthopaedic surgery to the leg or gynaecological surgery, death, or 30 September 2012 (see supplementary tables 1 and 2).

Pregnancies that ended before September 2012 were identified by hospital stays for birth or abortion (diagnosis and/or medical procedure) or by reimbursement of non-hospital medical abortion. We excluded women from the study at the estimated date of onset of pregnancy. To avoid attributing the well known excess risk of thromboembolism post partum to oral contraceptives use, and because the effective start of oral contraception after birth is uncertain, women with a first reimbursement for oral contraceptives occurring less than two months after delivery or abortion were entered into the cohort two months after the end of pregnancy.

\section{Definition of oral contraceptive use}

Data on oral contraceptive use was collected from records for reimbursement. We categorised drug use by combinations of progestogen and oestrogen (ethinylestradiol) doses. Eight combinations with 26 brand names are reimbursed in France (table 1), and oral contraceptives are dispensed by pharmacists to women for a maximum authorised period of three months. This maximum dispensing period was observed in $99.2 \%$ of cases in our cohort. To assess the specific effects of each progestogen and each oestrogen dose on outcome, we also studied the various combinations of oral contraceptives. We considered women who switched to another dose of oestrogen or switched progestogen to have changed drug group during follow-up. The period for use of oral contraceptives ranged from the date of first dispensing until the date of the next dispensing. We defined the discontinuation of treatment as more than three consecutive months without filling a prescription for oral contraceptives after the period covered by the last prescription. In this case, use of oral contraceptives ended three months after the period covered by the last prescription.

\section{Outcomes}

During follow-up we assessed hospital admissions for pulmonary embolism (ICD-10 code: I26), stroke (ICD-10 
codes: I63 with the exception of I63.6, I64), or myocardial infarction when initial management was specified by the medical staff (ICD-10 codes: I21.0 to 4, I21.9 plus indication of initial management). We also assessed the composite endpoint of hospital admission for pulmonary embolism, stroke, or myocardial infarction.

\section{Confounding factors}

In the database we identified potential baseline confounding factors known or likely to be related to cardiovascular events: age at study entry, complementary universal health insurance, deprivation index of participant's area of residence calculated from socioeconomic data for $2009,{ }^{34}$ consultation with a gynaecologist (at least one in the previous year), hypertension treated by antihypertensive drugs, and diabetes defined by at least two prescriptions of antidiabetic drugs in the previous 12 months or long term disease for diabetes. Data on smoking status were absent from the database, but some information about medical care related to tobacco use was present: a hospital discharge diagnosis related to tobacco use since 2006 (ICD-10 codes F17, Z71.6 and Z72.0) or dispensing of nicotine replacement therapy since 2009.

Because the proportion of women with diabetes or hypertension or treated for smoking cessation was small ( $<2 \%$ each), we combined these three factors in a single composite indicator of "contraindication or need for precautions for use” of oral contraceptives.

\section{Statistical analysis}

We calculated crude and age standardised incidence rates for pulmonary embolism, stroke, and myocardial infarction per 100000 women years for the eight progestogen and oestrogen combinations and for progestogen and oestrogen dose groups. Poisson regression was used to calculate the adjusted relative risk estimates of outcome rates with the various combined oral contraceptives. We also estimated relative risks by stratification according to oestrogen dose

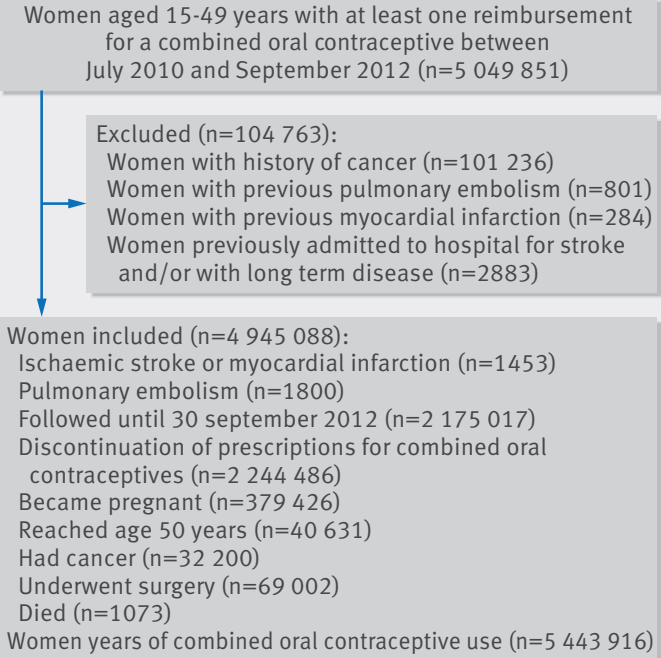

Fig 1 | Flow of participants through study
(30-40 $\mu \mathrm{g}$ or $20 \mu \mathrm{g}$ ). Lack of fit and over-dispersion were assessed by Pearson and deviance statistics. Interactions with age were tested and, when statistically significant, we carried out subgroup analyses when compatible with the number of events in each drug use group. For all analyses, we considered the type of oral contraceptives most commonly prescribed (that is, $30 \mu \mathrm{g}$ dose of oestrogen and levonorgestrel as progestogen) to be the reference group for drug use. We performed a secondary analysis in the subgroup of new users after pregnancy: postpartum women in whom pregnancy had ended less than six months (and more than two months) before study entry. Stratified analyses were performed according to consultation with a gynaecologist, complementary universal health insurance, oestrogen dose for progestogen type, and progestogen type for oestrogen dose.

We conducted several sensitivity analyses: for one we used a more specific definition of outcomes-confirmation that women who had not died 30 days after the event of interest had at least two prescriptions during the following four months (oral anticoagulant treatment after hospital admission for pulmonary embolism, antiplatelet agent after stroke, a combination of at least two drugs among antiplatelet agent, $\beta$ blocking agents, statin, angiotensin converting enzyme (ACE) inhibitor, or angiotensin receptor blocker (ARB) after myocardial infarction). For the other sensitivity analyses we used censoring of drug use just after the end of the period covered by the last dispensing, one month after, and women who did not switch drugs.

We considered P values of less than 0.05 to be statically significant. Statistical analyses were performed with SAS 9.3 software (SAS Institute, Cary, NC).

\section{Patient involvement}

No patients were involved in setting the research question or the outcome measures, nor were they involved in developing plans for recruitment, design, or implementation of the study. No patients were asked to advise on interpretation or writing up of results. There are no plans to disseminate the results of the research to study participants or the relevant patient community, although the French National Agency for Medicines and Health Products Safety (http://ansm.sante.fr/var/ ansm_site/storage/original/application/69261368479ccbb39b5a909842e4b4cc.pdf) and French National Health Insurance (www.ameli.fr/l-assurance-maladie/ statistiques-et-publications/etudes-en-sante-publique/ etudes-pharmaco-epidemiologiques/risques-sous-contraceptif-oral-combine.php) disseminate key findings from studies on their websites.

\section{Results}

After exclusion and censoring of data (figure 1), the study cohort comprised 4945088 women with 5443916 women years of oral contraceptive use.

The mean age of the women was 28.0 years (standard deviation 8.7 years) and almost $34 \%$ of the women used an oral contraceptive containing $20 \mu \mathrm{g}$ oestrogen. The four oral contraceptive combinations most commonly 
used were levonorgestrel with 30-40 $\mu \mathrm{g}$ oestrogen (58.3\% of women), levonorgestrel with $20 \mu \mathrm{g}$ oestrogen (15.3\%), desogestrel with $20 \mu \mathrm{g}$ oestrogen (13.9\%), and desogestrel with $30 \mu \mathrm{g}$ oestrogen (13.2\%). Specific participant characteristics were associated with each combination (table 2): younger women used levonorgestrel with $20 \mu \mathrm{g}$ oestrogen and desogestrel with $30 \mu \mathrm{g}$ oestrogen (mean age 25.3 and 25.7 years, respectively, with almost one third of women aged 15-19 years); women from higher socioeconomic groups used desogestrel with $20 \mu \mathrm{g}$ oestrogen and gestodene with 20 and $30 \mu \mathrm{g}$ oestrogen; women with a higher cardiovascular risk used levonorgestrel with 30-40 $\mu$ g oestrogen, norethisterone with $35 \mu \mathrm{g}$ oestrogen, and norgestrel with $50 \mu \mathrm{g}$ oestrogen. Follow-up by a gynaecologist varied considerably according to the oral contraceptive used, from $33.5 \%$ (levonorgestrel with $30-40 \mu$ g oestrogen) to $61.3 \%$ (gestodene with $20 \mu \mathrm{g}$ oestrogen). The distribution of oral contraceptives used by women post partum and the distribution of antimigraine drugs use according to oral contraceptive groups were also similar (table 2).

A total of 1800 pulmonary embolisms, 1046 ischaemic strokes, 407 myocardial infarctions, and 3253 composite events were observed during the study period. The respective absolute risk rates were 33, 19, 7, and 60 per 100000 women years of oral contraceptive use.

Women aged more than 35 years accounted for $26.1 \%$ of all oral contraceptive use and $56.7 \%$ of serious adverse events. Women with the lowest socioeconomic status presented a 1.4-fold, 1.5-fold, and 2.5-fold higher risk of pulmonary embolism, stroke, and myocardial infarction, respectively (see supplementary table 3).

After adjustment for progestogen and risk factors, the relative risks for women using low dose oestrogen (20 $\mu \mathrm{g} v$ 30-40 $\mu \mathrm{g}$ ) were 0.75 (95\% confidence interval 0.67 to 0.85 ) for pulmonary embolism, 0.82 (0.70 to 0.96 ) for ischaemic stroke, and 0.56 (0.39 to 0.79 ) for myocardial infarction (table 3 ). Using a low dose of oestrogen was inversely associated with pulmonary embolism for all three progestogens, although the association did not reach statistical significance among gestodene users (table 4). After adjustment for risk factors and oestrogen dose, desogestrel and gestodene were associated with statistically significantly higher relative risks of pulmonary embolism: 2.16 (1.93 to 2.41 ) and 1.63 (1.34 to 1.97), respectively, compared with levonorgestrel. Desogestrel and gestodene were also associated with a significantly higher risk for the composite endpoint of pulmonary embolism, stroke, or myocardial infarction: 1.59 (1.45 to 1.74 ) and 1.24 (1.06 to 1.46 ), respectively (table 3$)$. The associations between pulmonary embolism and progestogens provided similar results across strata of oestrogen dose (table 5). The crude and standardised rates of the events of interest and the effect of adjustment on the various confounders are shown (see supplementary tables 4 to 8 ).

Analysis of women post partum (two months to six months after delivery) also indicated a lower risk with using the $20 \mu \mathrm{g}$ dose of oestrogen compared with 30-40 $\mu \mathrm{g}$ for pulmonary embolism $(0.65,0.44$ to 0.94$)$ and for arterial events (ischaemic stroke or myocardial infarction)
(0.36, 0.20 to 0.62$)$. The adjusted relative risk of pulmonary embolism for desogestrel and gestodene (reference levonorgestrel) was 2.16 (1.52 to 3.03) and 1.49 (0.64 to 2.99), respectively (see supplementary table 9). Analyses stratified according to consultation with a gynaecologist and complementary universal health insurance provided similar results (see supplementary tables 10).

Several sensitivity analyses were performed. The first used a definition of endpoints confirmed by drug treatments prescribed after the event of interest (for example, anticoagulants after pulmonary embolism) (see supplementary table 11). Other sensitivity analyses used censoring of exposure just after the end of the period covered by the last dispensing and one month after (see supplementary tables 12 and 13). The analysis confined to women who did not switch drugs during follow-up was also performed (see supplementary table 14). These analyses demonstrated similar results for pulmonary embolism and arterial risk.

\section{Discussion}

In this population based cohort study, levonorgestrel with $20 \mu \mathrm{g}$ of oestrogen was associated with a statistically significantly lower risk of pulmonary embolism, ischaemic stroke, and myocardial infarction than levonorgestrel with 30-40 $\mu \mathrm{g}$ of oestrogen. For the same type of progestogen, using an oestrogen dose of $20 \mu \mathrm{g}$ compared with 30-40 $\mu \mathrm{g}$ was associated with a lower risk of pulmonary embolism (by 25\%), ischaemic stroke (by $18 \%$ ), and myocardial infarction (by 44\%). Desogestrel and gestodene were associated with 2.2-fold and 1.6-fold statistically significantly higher risks of pulmonary embolism compared with levonorgestrel. In contrast, the observed arterial vascular risks did not differ according to the type of progestogen used. Levonorgestrel with $20 \mu \mathrm{g}$ of oestrogen was globally associated with a lower risk of the composite endpoint of hospital admission for pulmonary embolism, stroke, or myocardial infarction compared with the other oral contraceptive combinations tested.

\section{Comparison with other studies}

Most authors have observed a dose-effect relation with oestrogen, higher doses being associated with an increased risk of venous thromboembolism. Lidegaard and colleagues ${ }^{12}$ showed that desogestrel or gestodene combined with $20 \mu \mathrm{g}$ of oestrogen was associated with $23 \%$ and $17 \%$ lower relative risks of venous thromboembolism compared with the same progestogens combined with $30 \mu \mathrm{g}$ of oestrogen. Van Hylckama and colleagues $^{7}$ reported a higher risk of venous thromboembolism for oral contraceptives containing $50 \mu \mathrm{g}$ of oestrogen compared with $30 \mu \mathrm{g}$ of oestrogen (odds ratio 1.9, 1.1 to 3.4), and no statistically significant difference for risk with oral contraceptives containing $20 \mu \mathrm{g}$ of oestrogen (0.8, 0.5 to 1.2). A similar trend has been shown for oral contraceptives with higher doses of oestrogen $(50-100 \mu \mathrm{g}){ }^{353637}$

In the present study, after adjustment for the type of progestogen, we observed a statistically significant 


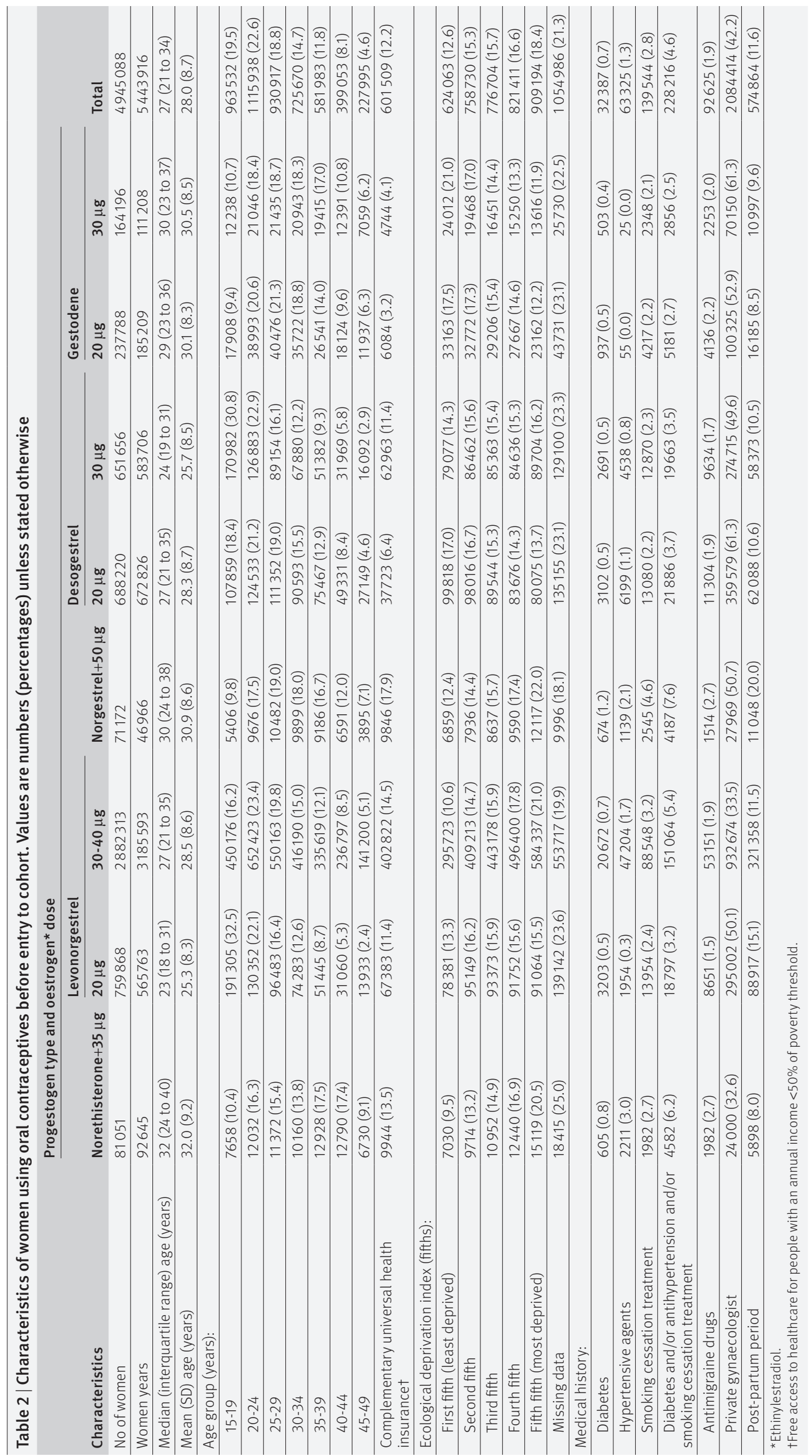




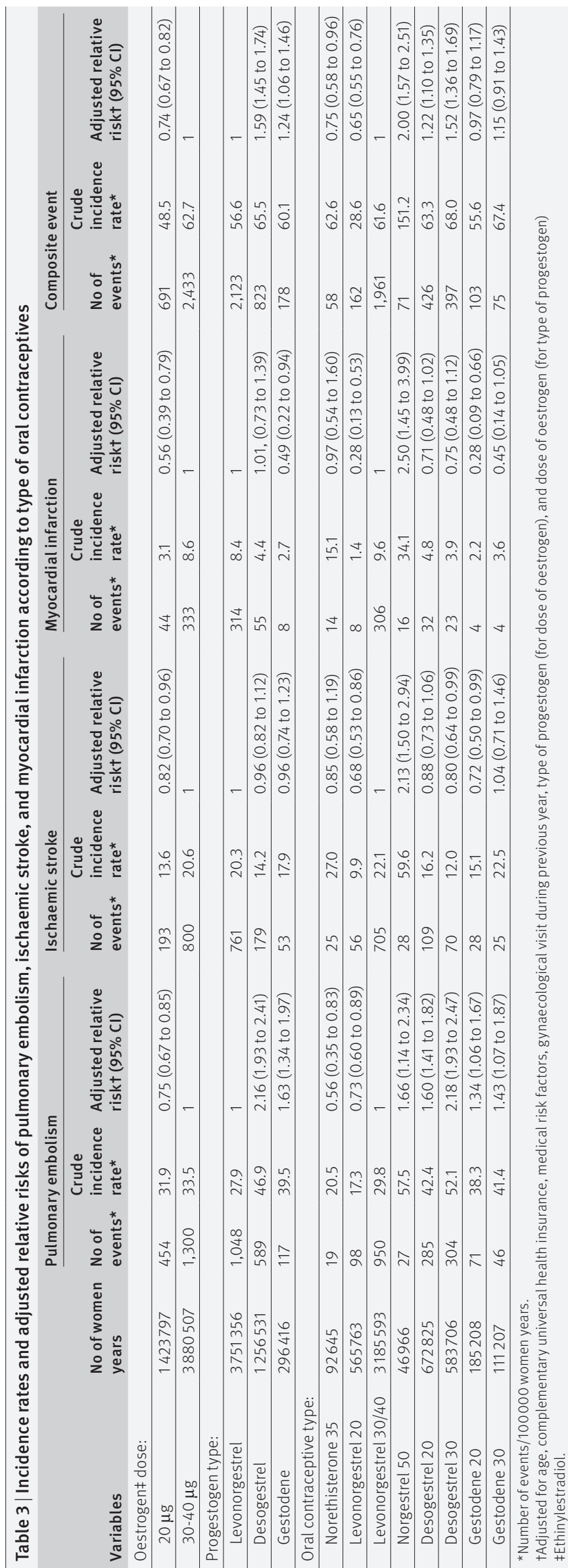

reduction in the risk of pulmonary embolism by about $25 \%$ with the $20 \mu \mathrm{g}$ dose compared with $30-40 \mu \mathrm{g}$ dose. A similar tendency was found for risk of venous thromboembolism with desogestrel and gestodene, but not with levonorgestrel. ${ }^{15}$ Finally, the analysis by Lidegaard and colleagues ${ }^{31}$ showed that oral contraceptives with $20 \mu \mathrm{g}, 30-40 \mu \mathrm{g}$, and $50 \mu \mathrm{g}$ of oestrogen were associated with relative risks of myocardial infarction of 1.40 (95\% confidence interval 1.07 to 1.81), 1.88 (1.66 to 2.13), and 3.73 (2.78 to 5.00), respectively ( $\mathrm{P}<0.001$ for trend). We also observed a statistically significantly lower risk for the $20 \mu \mathrm{g}$ dose compared with 30-40 $\mu \mathrm{g}$ doses (adjusted relative risk 0.56, 95\% confidence interval 0.39 to 0.79 ), in line with the results reported previously. ${ }^{31}$

Similarly, the relative risk of pulmonary embolism was 2.16 (1.93 to 2.41) for desogestrel and 1.63 (1.34 to 1.97) for gestodene compared with levonorgestrel. These relative risks were similar to those reported for risk of venous thromboembolism by Lidegaard and colleagues (2.2, 1.7 to 2.3 and $2.1,1.6$ to 2.8$)^{12}$; by van Hylckama and colleagues (2.0, 1.4 to 2.8 and 1.6, 1.0 to $2.4)^{7}$; in the meta-analysis by Stegeman and colleagues (1.8, 1.4 to 2.2 and $1.5,1.2$ to 2.0$)^{15}$; and by Vinogradova and colleagues ${ }^{18}(1.8,1.5$ to 2.1 and 1.5 , 1.2 to 1.9$)$.

The effect of age on the events of interest in this study is in line with those reported in the literature, supporting the validity of our reported results. For example, the 3.6-fold increased risk of venous thromboembolism with age (45-49 years $v 15-19$ years) calculated in by Lidegaard and colleagues ${ }^{8}$ was close to the risk of pulmonary embolism calculated in our study (4.1-fold). Similarly, the risks of ischaemic stroke and myocardial infarction with age (45-49 years $v$ 15-19 years) were the same in the two studies: 20 and 100, according to Lidegaard and colleagues ${ }^{31}$ and 21 and 106 in our study.

\section{Strengths and limitations of this study}

These results were shown with a high statistical power based on 5.4 million women years of combined oral contraceptive use, allowing us to observe more than 3200 serious events (pulmonary embolism, ischaemic stroke, or myocardial infarction) in this study. However, the number of events was low for some subgroups, particularly the number of myocardial infarctions among women treated with gestodene and levonorgestrel with $20 \mu \mathrm{g}$ of oestrogen. These results therefore need to be interpreted cautiously, and further studies are necessary to confirm the present results. The follow-up period was also relatively short (maximum of two years and three months), which limits the bias associated with changing diagnostic procedures and health system management of the three events of interest, and eliminated the potential time trend bias. However, certain diseases may take longer to manifest, particularly ischaemic stroke and myocardial infarction. The availability of levonorgestrel with $20 \mu \mathrm{g}$ of oestrogen on the French market in April 2010, with more than 650000 women years in our cohort, allowed 
Table 4 | Adjusted relative risks of pulmonary embolism according to oestrogen dose stratified by type of progestogen

\begin{tabular}{|c|c|c|c|c|}
\hline \multirow[b]{2}{*}{ Progestogen } & \multicolumn{2}{|c|}{ Oestrogen* $20 \mu \mathrm{g}$} & \multicolumn{2}{|c|}{ Oestrogen* $30-40 \mu \mathrm{g}$} \\
\hline & No of events & $\begin{array}{l}\text { Adjusted relative } \\
\text { riskt }(95 \% \mathrm{Cl})\end{array}$ & No of events & $\begin{array}{l}\text { Adjusted relative } \\
\text { riskt }(95 \% \mathrm{Cl})\end{array}$ \\
\hline Levonorgestrel & 98 & 0.74 (0.59 to 0.91) & 950 & 1 \\
\hline Desogestrel & 285 & 0.75 (0.63 to 0.88$)$ & 304 & 1 \\
\hline Gestodene & 71 & 0.94 (0.68 to 1.29$)$ & 46 & 1 \\
\hline
\end{tabular}

No significant interaction between progestogen and oestrogen dose.

*Ethinylestradiol.

tAdjusted for age, complementary universal health insurance, medical risk factors, and gynaecological visit during previous year.
A validation study of cases of pulmonary embolism in 25 French hospitals found that the sensitivity of the ICD-10 diagnostic code for pulmonary embolism in the PMSI was $88.9 \%$ (95\% confidence interval 85.6 to 92.2)..$^{40}$ Our analysis of anticoagulant treatment on discharge from hospital (89\% of cases filled at least two prescriptions, with an average of more than five prescriptions, for anticoagulants during the four months after hospital admission) confirmed the validity of this criterion. The authors of a validation study of cases of stroke based on the PMSI compared with the stroke registry reported a sensitivity of $77.1 \%$ (95\% confidence interval 74.2 to 80 ) and a positive predictive value of $69.2 .{ }^{41}$ However, an improvement was observed over time, with a sensitivity of $82.9 \%$ and positive predictive value of $81.2 \%$ in 2008 , the last year of the study. A classic difficulty in observational studies on stroke concerns interpretation of the I64 code (stroke, not specified as haemorrhage or infarction). This code made a limited contribution to the present study, as it represented only 102 of the 1046 ischaemic strokes compared with 944 of I63 codes (with the exception of I63.6).

The initial management of myocardial infarction has a specific code in the French hospital discharge database based on ICD-10 to distinguish initial management from a prevalent case by means of a mandatory additional digit. As this code has a major impact on the cost of hospital stay, the initial management of myocardial infarction seems to be associated with a relatively low risk of error, especially in young participants. We also observed that more than $94 \%$ of women in this study received outpatient post-infarction treatment comprising at least two treatment groups from among statins, $\beta$ blockers, angiotensin converting enzyme inhibitors/sartans, and platelet aggregation inhibitors.

However, our study has several limitations. The first concerns the absence of the start date for use of combined oral contraceptives and the concept of new user or switch from another product not reimbursed by French national health insurance. Indeed, the incidence of venous thromboembolism is increased during the initial phase of oral contraceptives use, particularly during the first three months and the first year. ${ }^{12}$ An adjustment for the length of oral contraceptives use would be necessary to take this variable into account. Lidegaard and colleagues, who performed this adjustment, observed a slight reduction in the relative risk for new products, but the global results ane of oral contraceptives. Valida of cases is essential in this type of observational study.

\begin{tabular}{|c|c|c|c|c|c|c|}
\hline \multirow[b]{2}{*}{$\begin{array}{l}\text { Oestrogen* } \\
\text { dose }\end{array}$} & \multicolumn{2}{|c|}{ Levonorgestrel } & \multicolumn{2}{|l|}{ Desogestrel } & \multicolumn{2}{|l|}{ Gestodene } \\
\hline & No of events & $\begin{array}{l}\text { Adjusted relative } \\
\text { riskt }(95 \% \mathrm{Cl})\end{array}$ & No of events & $\begin{array}{l}\text { Adjusted relative } \\
\text { riskt }(95 \% \mathrm{Cl})\end{array}$ & No of events & $\begin{array}{l}\text { Adjusted relative } \\
\text { riskt }(95 \% \mathrm{Cl})\end{array}$ \\
\hline $20 \mu \mathrm{g}$ & 98 & 1 & 285 & 2.30 (1.86 to 2.86$)$ & 71 & 1.96 (1.47 to 2.61$)$ \\
\hline $30-40 \mu \mathrm{g}$ & 950 & 1 & 304 & 2.19 (1.93 to 2.48$)$ & 46 & 1.41 (1.05 to 1.84$)$ \\
\hline
\end{tabular}


remained unchanged. If this factor had a major impact, it would have primarily concerned levonorgestrel with $20 \mu$ g oestrogen, the product most recently released onto the French market, for which the risk of pulmonary embolism would possibly be overestimated, although we observed a lower risk than with the other drug combinations. The frequently reported argument that third generation oral contraceptives such as gestodene, desogestrel that have been released onto the market more recently and therefore correspond to newer users, would lead to bias, ${ }^{42}$ can no longer be justified more than 25 years after the release of these oral contraceptives in France. The relative stability of the market shares of the various oral contraceptives other than levonorgestrel with $20 \mu$ g oestrogen in France between July 2010 and September 2012 is an argument in favour of the validity of our estimates. Another element concerns the analysis in the post-partum setting, in which all women of the cohort initiated use of oral contraceptives after the pregnancy. The results of this subgroup analysis were similar to those of the main analysis for desogestrel compared with levonorgestrel as reference.

In contrast, to our knowledge the duration of use had no impact on the risk of myocardial infarction and ischaemic stroke-the other two events of interest in the study.

Among the limitations related to the study design, we failed to take into account women who may have died from a venous or arterial thromboembolic event before admission to hospital. This limitation could introduce a bias if women experiencing a thromboembolic event while taking a combined oral contraceptive with $20 \mu \mathrm{g}$ of oestrogen died more rapidly and before admission to hospital compared with women taking one with 30-40 $\mu \mathrm{g}$ of oestrogen, which seems unlikely.

Potential for confounding by indication is a another limitation of the present study, as we did not take into account some factors known to increase the risk of venous or arterial thrombosis and which may therefore influence a doctor's choice of oral contraceptives, such as body mass index and family predisposition. However, doctors preferentially prescribed levonorgestrel to the most economically underprivileged women and women with diabetes, two factors associated with higher body mass index. In the present study these two factors would underestimate the risk of pulmonary embolism associated with the other progestogens such as desogestrel and gestodene. The same argument could apply to women with a family predisposition, who would be prescribed oral contraceptives associated with a lower risk. Data on smoking, a major risk factor for arterial thrombosis, but with a low impact on the risk of venous thromboembolism, ${ }^{43}$ were only partially available and limited to situations of medically assisted smoking cessation. Again, the population most concerned by smoking was that using levonorgestrel, an argument in favour of underestimation of the risk associated with the other oral contraceptive combinations. Furthermore, analyses adjusted for smoking in previous published studies did not modify, or only marginally modified, the results. ${ }^{731}$

Finally, another limitation of this study was the failure to include oral contraceptives not reimbursed by French national health insurance, such as drospirenone for which discordant result have been previously

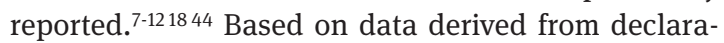
tions of annual sales by drug companies to the French National Agency for Medicines and Health Products Safety, we estimated that our study sample comprised about two thirds of all women receiving a third generation oral contraceptive and all women receiving a first or second generation oral contraceptive. Limiting our study to women using oral contraceptives reimbursed by French national health insurance has the advantage of improving the comparability of women within the sample, as it has been largely shown in the literature that the choice of method of contraception is related to women's socioeconomic status as well as financial imperatives. ${ }^{45}$

Lastly, only pulmonary embolism was considered as an outcome of deep vein thrombosis, although use of oral contraceptives increases the risk of all forms of deep vein thrombosis. ${ }^{8}$ Indeed, acute diagnoses can be determined only for hospital related events in the present databases, and the frequency of deep vein thrombosis, of which not all cases involve hospital admission, would have been seriously underestimated.

\section{Conclusions}

Women using an oral contraceptive with $20 \mu \mathrm{g}$ of oestrogen had a lower risk of pulmonary embolism and serious arterial thromboembolic events than women using an oral contraceptive with 30-40 $\mu \mathrm{g}$ oestrogen. We also found that use of an oral contraceptive containing levonorgestrel was associated with a 50\% lower risk of pulmonary embolism compared with using an oral contraceptive with a third generation progestogen. The combination of levonorgestrel and $20 \mu \mathrm{g}$ of oestrogen was the combination associated with the lowest incidence of serious adverse events. Under real conditions of use, among 100000 women using a combined oral contraceptive for one year an estimated 33 will experience pulmonary embolism, 19 ischaemic stroke, and seven myocardial infarction. For each woman, it is necessary to determine the most appropriate contraceptive method in terms of acceptability and risk. A risk reduction strategy should be based on limitation of use of oral contraceptives associated with the highest risk to decrease the incidence of pulmonary embolism $^{46}$ and arterial thromboembolic events among young women.

We thank Anthony Saul for English revision of the manuscript. Contributors: This study was conducted at the official request of the French Ministry of Health. MZ, PR, FA, and AW had the idea for the study. AW and MZ conceived the study design. AW planned the study and drafted the manuscript. MD performed data management. $M D$ and PB did the statistical analyses. AW and MZ were responsible for management of the project and oversaw the study. All authors contributed to the interpretation of the data, revised the manuscript, and approved the final manuscript. AW and MD are the guarantors. 
Funding: This research was funded by the French National Health Insurance Fund (CNAMTS) and the French National Agency for Medicines and Health Products Safety (ANSM). AW, MD, PB, JR, PR, and FA are employees of the French National Health Insurance Fund, $\mathrm{MZ}$ and FR of the French National Agency for Medicines and Health Products Safety. The present paper represents the opinions of the authors and does not necessarily reflect the position of their employers.

Competing interests: All authors have completed the ICMJE uniform disclosure form at www.icmje.org/coi_disclosure.pdf and declare: no support from any organisation for the submitted work; no financial relationships with any organisations that might have an interest in the submitted work in the previous three years; no other relationships or activities that could appear to have influenced the submitted work.

Ethical approval: This study was approved by the French data protection agency Commission Nationale de l'Informatique et des Libertés (regulatory decision DE-2011-078).

Data sharing: No additional data available.

Transparency: The lead author affirms that this manuscript is an honest, accurate and transparent account of the study being reported; that no important aspects of the study have been omitted; and that any discrepancies from the study as planned (and, if relevant, registered) have been explained.

This is an Open Access article distributed in accordance with the Creative Commons Attribution Non Commercial (CC BY-NC 3.0) license, which permits others to distribute, remix, adapt, build upon this work non-commercially, and license their derivative works on different terms, provided the original work is properly cited and the use is non-commercial. See: http://creativecommons.org/licenses/ by-nc/3.0/

1 Compiled by Earth Policy Institute from U.N. Population Division. World Contraceptive Use 2011, wall chart, February 2011.

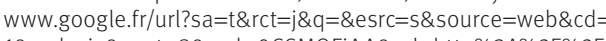
$1 \&$ cad=rja\&uact=8\&ved =0CCMQFjAA\&url=http $\% 3 \mathrm{~A} \% 2 \mathrm{~F} \% 2 \mathrm{~F}$ www.earth-policy.org\%2Fdatacenter\%2Fxls\%2Fhighlights26_all. xls\&ei=FZOWVKPMOdTvaKXzgqgP\&usg=AFQjCNF10wNQtG 2aoPUgkK9YRymHRxb5cw\&sig2=ZpqOHEY2CTVVkIA 9WUrS4Q\&bvm=bv75097201,d d2s

2 Vandenbroucke JP, Koster T, Briët E, Reitsma PH, Bertina RM, Rosendaal FR. Increased risk of venous thrombosis in oralcontraceptive users who are carriers of factor $\mathrm{V}$ Leiden mutation. Lancet 1994;344:1453-7. doi:10.1016/S0140-6736(94)90286-0.

3 Thorogood M, Mann J, Murphy M, Vessey M. Risk factors for fatal venous thromboembolism in young women: a case-control study. Int J Epidemiol 1992;21:48-52. doi:10.1093/ije/21.1.48.

4 World Health Organization Collaborative Study of Cardiovascular Disease and Steroid Hormone Contraception. Venous thromboembolic disease and combined oral contraceptives: results of international multicentre case-control study. Lancet 1995;346:157582. doi:10.1016/S0140-6736(95)91926-0.

5 Farmer RD, Lawrenson RA, Thompson CR, Kennedy JG, Hambleton IR. Population-based study of risk of venous thromboembolism associated with various oral contraceptives. Lancet 1997;349:83-8. doi:10.1016/S0140-6736(96)07496-X.

6 Parkin L, Skegg DCG, Wilson M, Herbison GP, Paul C. Oral contraceptives and fatal pulmonary embolism. Lancet 2000;355:2133-4. doi:10.1016/S0140-6736(00)02382-5.

7 van Hylckama Vlieg A, Helmerhorst FM, Vandenbroucke JP, Doggen C), Rosendaal FR. The venous thrombotic risk of oral contraceptives, effects of oestrogen dose and progestogen type: results of the MEGA case-control study. BMJ 2009;339:b2921. doi:10.1136/bmj. b2921.

8 Lidegaard $\emptyset$, Løkkegaard E, Svendsen AL, Agger C. Hormonal contraception and risk of venous thromboembolism: national follow-up study. BM/ 2009;339:b2890. doi:10.1136/bmj.b2890.

9 Dinger J, Assmann A, Möhner S, Minh TD. Risk of venous thromboembolism and the use of dienogest- and drospirenonecontaining oral contraceptives: results from a German case-control study. I Fam Plann Reprod Health Care 2010;36:123-9. doi:10.1783/147118910791749416.

10 Parkin L, Sharples K, Hernandez RK, Jick SS. Risk of venous thromboembolism in users of oral contraceptives containing drospirenone or levonorgestrel: nested case-control study based on UK General Practice Research Database. BMJ 2011;342:d2139. doi:10.1136/bmj.d2139.

11 Jick SS, Hernandez RK. Risk of non-fatal venous thromboembolism in women using oral contraceptives containing drospirenone compared with women using oral contraceptives containing levonorgestrel: case-control study using United States claims data. BM! 2011;342:d2151. doi:10.1136/bmj.d2151.
12 Lidegaard $\varnothing$, Nielsen LH, Skovlund CW, Skjeldestad FE, Løkkegaard E. Risk of venous thromboembolism from use of oral contraceptives containing different progestogens and oestrogen doses: Danish cohort study, 2001-9. BMJ 2011;343:d6423. doi:10.1136/bmj.d6423.

13 Food and Drug Administration Office of Surveillance and Epidemiology. Combined hormonal contraceptives (CHCs) and the risk of cardiovascular disease endpoints (http://www.fda.gov/ downloads/Drugs/DrugSafety/UCM277384.pdf)

14 Gronich N, Lavi I, Rennert G. Higher risk of venous thrombosis associated with drospirenone-containing oral contraceptives: a population-based cohort study. CMAI 2011;183:E1319-25 doi:10.1503/cmaj.110463.

15 Stegeman BH, de Bastos M, Rosendaal FR, et al. Different combined oral contraceptives and the risk of venous thrombosis: systematic review and network meta-analysis. BMJ 2013;347:\$5298. doi:10.1136/ bmj.f5298.

16 Dunn N. Oral contraceptives and venous thromboembolism. BM 2009;339:b3164. doi:10.1136/bmj.b3164.

17 Bitzer J, Amy JJ, Beerthuizen R, et al. Statement on combined hormonal contraceptives containing third- or fourth-generation progestogens or cyproterone acetate, and the associated risk of thromboembolism. J Fam Plann Reprod Health Care 2013;39:156-9. doi:10.1136/ jfprhc-2013-100624.

18 Vinogradova Y, Coupland C, Hippisley-Cox J. Use of combined oral contraceptives and risk of venous thromboembolism: nested case-control studies using the QResearch and CPRD databases. BMJ 2015:350:h2135. doi:10.1136/bmi.h2135.

19 Poulter NR, Chang CL, Farley TM, Marmot MG, Meirik O. WHO Collaborative Study of Cardiovascular Disease and Steroid Hormone Contraception. Effect on stroke of different progestagens in low oestrogen dose oral contraceptives. Lancet 1999;354:301-2. doi:10.1016/S0140-6736(99)01013-2.

20 Heinemann LAJ, Lewis MA, Spitzer WO, Thorogood M, GuggenmoosHolzmann I, Bruppacher R. Transnational Research Group on Oral Contraceptives and the Health of Young Women. Thromboembolic stroke in young women. A European case-control study on oral contraceptives. Contraception 1998;57:29-37. doi:10.1016/ S0010-7824(97)00204-7.

21 Lidegaard $\varnothing$, Kreiner $S$. Contraceptives and cerebral thrombosis: a five-year national case-control study. Contraception 2002;65: 197-205. doi:10.1016/S0010-7824(01)00306-7.

22 Stampfer MJ, Willett WC, Colditz GA, Speizer FE, Hennekens CH. A prospective study of past use of oral contraceptive agents and risk of cardiovascular diseases. N Engl / Med 1988;319:1313-7. doi:10.1056/ NEJM198811173192004.

23 Lewis MA, Heinemann LAJ, Spitzer WO, MacRae KD, Bruppacher R. The use of oral contraceptives and the occurrence of acute myocardial infarction in young women. Results from the Transnational Study on Oral Contraceptives and the Health of Young Women. Contraception 1997;56:129-40. doi:10.1016/ S0010-7824(97)00118-2.

24 Poulter NR, Chang CL, Farley TMM, Kelaghan J, Meirik O, Marmot MG. WHO Collaborative Study of Cardiovascular Disease and Steroid Hormone Contraception. Acute myocardial infarction and combined oral contraceptives: results of an international multicentre case-control study. Lancet 1997;349:1202-9. doi:10.1016/ S0140-6736(97)02358-1.

25 Sidney S, Siscovick DS, Petitti DB, et al. Myocardial infarction and use of low-dose oral contraceptives: a pooled analysis of 2 US studies. Circulation 1998;98:1058-63. doi:10.1161/01.CIR.98.11.1058.

26 Dunn N, Thorogood M, Faragher B, et al. Oral contraceptives and myocardial infarction: results of the MICA case-control study. BMJ 1999;318:1579-83. doi:10.1136/bmj.318.7198.1579.

27 Dunn NR, Arscott A, Thorogood M. The relationship between use of oral contraceptives and myocardial infarction in young women with fatal outcome, compared to those who survive: results from the MICA case-control study. Contraception 2001;63:65-9. doi:10.1016/ S0010-7824(01)00172-X.

28 Rosenberg L, Palmer JR, Rao RS, Shapiro S. Low-dose oral contraceptive use and the risk of myocardial infarction. Arch Intern Med 2001;161:1065-70. doi:10.1001/archinte.161.8.1065.

29 Tanis BC, van den Bosch MA, Kemmeren JM, et al. Oral contraceptives and the risk of myocardial infarction. N Engl J Med 2001;345:1787-93. doi:10.1056/NEJMoa003216

30 Margolis KL, Adami HO, Luo J, Ye W, Weiderpass E. A prospective study of oral contraceptive use and risk of myocardial infarction among Swedish women. Fertil Steril 2007;88:310-6. doi:10.1016/j. fertnstert.2006.11.206

31 Lidegaard $\varnothing$, Løkkegaard E, Jensen A, Skovlund CW, Keiding N. Thrombotic stroke and myocardial infarction with hormonal contraception. N Engl J Med 2012;366:2257-66. doi:10.1056/ NEJMoa1111840.

32 Tuppin P, de Roquefeuil L, Weill A, Ricordeau P, Merlière Y. French national health insurance information system and the permanent beneficiaries sample. Rev Epidemiol Sante Publique 2010;58:28690. doi:10.1016/j.respe.2010.04.005. 
33 Moulis G, Lapeyre-Mestre M, Palmaro A, Pugnet G, Montastruc JL, Sailler L. French health insurance databases: What interest for medical research?Rev Med Interne 2015;36:411-7. doi:10.1016/j. revmed.2014.11.009.

34 Rey G, Jougla E, Fouillet A, Hémon D. Ecological association between a deprivation index and mortality in France over the period 1997 - 2001 variations with spatial scale, degree of urbanicity, age, gender and cause of death. BMC Public Health 2009;9:33. doi:10.1186/1471-2458-9-33.

35 Vessey M, Mant D, Smith A, Yeates D. Oral contraceptives and venous thromboembolism: findings in a large prospective study. BrMedJ (Clin Res Ed) 1986;292:526. doi:10.1136 bmj.292.6519.526.

36 Bloemenkamp KW, Rosendaal FR, Helmerhorst FM, Büller HR, Vandenbroucke JP. Enhancement by factor V Leiden mutation of risk of deep-vein thrombosis associated with oral contraceptives containing a third-generation progestagen. Lancet 1995:346:1593-6. doi:10.1016/S0140-6736(95)91929-5.

37 Gerstman BB, Piper JM, Tomita DK, Ferguson WJ, Stadel BV, Lundin FE. Oral contraceptive estrogen dose and the risk of deep venous thromboembolic disease. Am J Epidemiol 1991;133:32-7.

38 Haute Autorité de Santé. Correct use of medicinal products: Combined oral contraceptives: prefer 1st or 2 nd generation pills. November 2012. www.hassante.fr/portail/upload/docs/application/ pdf/2012-12/contraceptis_oraux_3_g_fiche_bum.pdf

39 French Ministry of Labour. Employment and Health. Guide to the methodology of production of information on medical activity and billing in medicine, surgery, obstetrics and dentistry. Official Bulletin No. 2011/6 b. Special issue. June 2011. www.sante.gouv.fr/IMG/pdf/ sts_20110006_0001_p000.pdf
40 Casez P, Labarère J, Sevestre MA, et al. ICD-10 hospital discharge diagnosis codes were sensitive for identifying pulmonary embolism but not deep vein thrombosis. / Clin Epidemiol 2010;63:790-7. doi:10.1016/j.jclinepi.2009.09.002.

41 Aboa-Eboulé C, Mengue D, Benzenine E, et al. How accurate is the reporting of stroke in hospital discharge data? A pilot validation study using a population-based stroke registry as control. J Neurol 2013;260:605-13. doi:10.1007/s00415-012-6686-0

42 Suissa S, Spitzer WO, Rainville B, Cusson J, Lewis M, Heinemann L. Recurrent use of newer oral contraceptives and the risk of venous thromboembolism. Hum Reprod 2000;15:817-21. doi:10.1093/ humrep/15.4.817.

43 Zhang G, Xu X, Su W, Xu Q. Smoking and risk of venous thromboembolism: a systematic review. SoutheastAsian J Trop Med Public Health 2014;45:736-45

44 Dinger JC, Heinemann LA, Kühl-Habich D. The safety of a drospirenone-containing oral contraceptive: final results from the European Active Surveillance Study on oral contraceptives based on 142,475 women-years of observation. Contraception 2007;75:344-54. doi:10.1016/i.contraception.2006.12.019.

45 Bajos N, Bohet A, Le Guen M, Moreau C. Fecond Survey Team. Contraception in France: new context, new practices?Popul Soc (Paris) 2012;492. www.ined.fr/fichier/t_publication/1606/publi_pdf2 pesa492.pdf.

46 Tricotel A, Collin C, Zureik M. Impact of the sharp changes in the use of contraception in 2013 on the risk of pulmonary embolism in France. I Thromb Haemost 2015;13:1576-80. doi:10.1111/jth.13053.

(C) BMJ Publishing Group Ltd 2016

Web appendix: Supplementary information 